\title{
Human Capital as a Key Factor of Enterprise Efficiency
}

\author{
Vladimir I. Malyuk \\ Institute of Industrial Management, \\ Economy and Trade \\ Peter the Great St. Petersburg \\ Polytechnic University \\ St.Petersburg, Russian Federation \\ malyuk.vi@gmail.com
}

\author{
Elizaveta A. Zotova \\ Institute of Industrial Management, \\ Economy and Trade \\ Peter the Great St. Petersburg \\ Polytechnic University \\ St.Petersburg, Russia \\ zotova@kafedrapik.ru
}

\author{
Manfred Esser \\ Get IT \\ Saint-Petersburg, Russia \\ messer@myget-it.com
}

\begin{abstract}
Organizational development strategies are implemented with the involvement of significant resources for an enterprise. Taking into account the limitations of all types of resources available to an organization, the task of their rational use is very relevant and is solved continuously. Management decisions on allocating investment resources between development projects, determining their reasonable amounts in each direction of development are becoming more accurate due to the use of economic and mathematical models that describe various processes occurring in an organization. One of the most important resources of an organization is its employees. The quality of labor resource directly determines the competitiveness of an enterprise in the market. The main part of this quality level can be attributed to the human capital accumulated by the employees of an enterprise throughout their life. Only a high-quality labor resource of an organization can ensure high efficiency of a company's business, its stable position in the market. However, it should be understood that the growth or maintenance of an acceptable quality level of the labor potential of an enterprise requires certain investment, which should also be justified. This paper is dedicated to the methods of evaluating the effectiveness of investments in the development of the labor potential of an enterprise.
\end{abstract}

Keywords-economic and mathematical modeling, enterprise development, human capital, labor potential of an enterprise, quality of a labor resource, reasonable investment

\section{INTRODUCTION}

In recent decades, a special role is attributed to labor resources when development of social and economic systems is analyzed. For example, the Nobel laureate of 1979, T. Schultz (1902-1998) in his research focused on the development of the personal capital of an individual, which is formed throughout his life and is associated with improving his education, broadening his outlook, gaining experience in the chosen field of expertise, etc. Schultz proved that the American economy for a long time received a higher income from "human" capital, and not from material one [1]. For that reason, investing in the development of "human capital", according to Schultz, gives a greater return than investment in equipment, technology, construction of factories, etc. So in developed countries, a one year increase in the duration of education leads to a GDP growth of $5-15 \%$.

It is clear that growth of human capital must be accompanied by certain investments. An individual invests in education, mastering a profession, and gaining work experience... All of it costs money, and sometimes investments are quite high. At the same time, the person hopes that the investments will pay off later in his life. However, it should be recognized that today, people who have decided to increase their human capital, often do not have all the information about the prospects of their investment. A young person who enrolls in a higher education institution has frequently a dim idea about his future work. Making mistake in choosing a future field of activity, of course, creates a certain risk of not returning the funds invested in the growth of human capital. It is also possible that conditions in the labor market will change during the period when a person is improving the quality of his human capital. At the same time, it is necessary to take into account the fact that in the modern dynamically changing external environment, acquired knowledge and skills morally age very fast. The learning process can take quite a while, sometimes an entire life (an obvious characteristic of a university teacher). Studies conducted by two Nobel laureates T. Schultz and G. Becker (won a Nobel prize in 1992 for his work on the theory of human capital and active journalistic activity) showed that, in general, investments in the development of human capital have an average rate of return which is higher or comparable to this indicator in the manufacturing industry. According to G. Becker [2], it is 10$15 \%$, although it can be significantly higher (up to $30-50 \%$ ) for a goal-oriented person who has correctly defined the area in which he is going to build a career. Given that education expenditures make up 6-7\% of GDP, it is obvious that investment in education is highly efficient. There are other positive effects that accompany growth of human capital, such as better working conditions, a creative nature of production activities, a possibility of building a professional career, etc. This factor determined the growth of investments in human capital. For example, in the US, the share of investment in human capital is more than $15 \%$ of GDP, which exceeds private investment in fixed assets (factories, equipment, warehouses) [3]. In the United States, the growth of the education level of the nation provides a $15 \%$ increase in national income.

According to studies [4], the profitability of education, which is the main way to increase human capital, is different. There is data that the coefficient of return on private investment in education (profitability of education) for a bachelor's degree was $13.4 \%$, for a master's degree $7.2 \%$, for a Ph.D. - 6.6\% [5]. In the OECD countries, 
according to information given in source [5], the rate of return of primary education was $23 \%$, secondary $-15 \%$, and higher - $11 \%$. In the countries of Western Europe and the USA a diploma of a prestigious business school can double the price of its holder in the labor market [6]. At the same time, the statistics data gathered by Becker indicates that the growth in the level of education by 1 grade of secondary school provides an average increase in the number of rationalization proposals by $6 \%$ and reduces the time taken by workers for learning how to carry out new operations by $50 \%$.

It should be considered that many companies pay for advanced training of their employees, i.e. in fact, invest in the growth of their personal human capital. For example, General Electric spends more than $\$ 100$ million for these purposes annually. In general, in the United States private companies spend more than $\$ 30$ billion a year on professional training, which exceeds respective public expenses [7, p.120]. These costs should be considered as an investment in the growth of labor quality of an enterprise, which must be returned. According to the definition by B. M. Genkin [7, p.126] the labor quality should be understood as the degree to which its characteristics comply with the requirements arising from the goals and operational environment of an enterprise, as well as with the requirements of human development and social relations in society.

\section{METHODS}

We believe that the management team of an enterprise would be interested in being able to estimate the effectiveness of such investments. These estimates are reduced to a comparison of funds invested in increase in labor quality $\mathrm{I}_{1 . \mathrm{q}}$ and efficiency of investments $\mathrm{E}_{\mathrm{i}}$, i.e. the additional income provided by such an increase or $I_{\text {l.q. }} \leq E_{i}$, the return must be non-negative. Today, there is a lack of methods that allow us to assess the effectiveness of investments in the development of human capital in organizations.

The source [ 8 p. 262] presents data that in the USA in 1960-1980 the rate of return of formal education was 10 $15 \%$, the rate of return of "potential" experience was $8-10 \%$. The analysis of the results of monitoring of economic development and public health in the Russian Federation shows that in 1990 the corresponding rates of return were 6$8 \%$ and $2-3 \%$. Thus, financing the development of the social sphere, education, health care, culture, etc., becomes countable, economically rational and, after all, politically demanded. It is investments in "human capital", and in a growth of the value of human labor that become the most important factors of economic transformation, modernization of economic and legal institutions. Human capital obtains the status of the most important factor for economic growth.

In the further reasoning, we will assume that the whole process of organizational development can be viewed as a certain sequence of projects, whose effectiveness is assessed according to the degree of rationality of the allocated amount of investment within the existing limits and its effective use in achieving goals. In this case, a variety of projects that can improve the competitiveness of the enterprise has to be simulated. Models should allow us to determine how efficiently the limited resources of an organization (investment in organizational development) are used. In this paper an attempt is made to estimate the main characteristics of an investment project and how they are affected by the quality level of the labor resources of the enterprise. Economic and mathematical modeling methods are used to tackle the task.

Works [10, p.195], [13, p.31; 10], [16] show the possibility and acceptability of the description of the dependence of the return on investment on their volume based on curves with saturation or S-curves (Fig. 1). Smodels can be graphically built using retrospective data on the economic activity of the enterprise. Using the empirical dependence, we can make a theoretical model, whose formula is based on the Verhulst model [12], [15], modified in a form acceptable for practical use [11, p.198], [15]. We called it the updated Verhulst model (1):

$$
Y=\frac{A \cdot 10^{a}}{1+10^{a}}\left(\frac{1-10^{-b x}}{1+10^{a-b x}}\right),
$$

where $x$ is the investment in the project of the organization development;

$Y$ is the return on investment;

$a, b, A$ are the coefficients determining the shape and position of the S-curve in a given coordinate field.

If the S-curve shown in Fig. 1 is superimposed with a straight line drawn from the origin at an angle of $45^{\circ}$ to the axes, then it becomes possible to determine the rational investment interval for the company's development project $[12$, p.140]. The points of intersection of the S-curve with this line are the break-even points in this production process. This is proved quite simply. For example, when investment in production is $I_{2}$, return on investment in the amount of $V_{2}$ will be obtained, it is obvious that $I_{2}=V_{2}$ (curve $b$ in Fig. 1). This is the first point of return. As we see in Figure 1, there is one more intersection point, which corresponds to $\mathrm{I}_{4}$. This is the second point of return. It is of theoretical interest, and from a practical point of view, it is less useful because this point implies a very significant range of activity in the framework of the project. This point is not formally defined today. We should note that the analysis of economic processes occurring in social and economic systems based on S-models is a more general approach than the well-known linear model of breakeven analysis (determining the break-even point). Such a linear model is valid only for the central part of the S-curve, which lies near the first point of return (point 2 in Fig. 1) or approximately in the interval between points 1 and 3 . It is clear that the total production costs should be covered by the investment made, i.e. $I=C_{\Sigma}=C_{\text {fix }}+C_{\text {var }} \cdot N$. However, with an increase in the level of production activity (to the right of point 3 on the "b" curve in Fig. 1), semi-fixed costs begin to grow due to the need to introduce new capacities, increase the volumes of materials and components involved, which leads to an increase in transportation costs, transactional costs, the increase in management costs while the controllability of the object is decreasing (the known example of the plant construction by G. Ford in River Rouge 
$[9$, p.208). This growth reduces the return on investment down to zero values (point 4 in Fig. 1). A further increase in the level of economic activity of the enterprise will result in losses. It is necessary to point out a relative decline in direct variable costs of the enterprise due to gaining practical experience (productivity growth, reduction of rejects, optimization of the product design, development of the technical process, etc.). However, the growth rate of the semifixed part of costs, apparently, is much higher than the reduction rate of their variable part. Similar reasoning can be given about the S-curve section, which lies to the left of the first point of return (point 2 in Fig. 1). When production volumes are small, semi-fixed costs do not get covered up to the first point of return. The dependence has linear nature only near this point.

The scheme shown in Figure 1 allows us to determine the interval of rational investment. It is individual for every enterprise and depends mainly on labor quality. So for the team, displayed by curve "b", this interval corresponds to $\mathrm{I}_{2} \div \mathrm{I}_{4}$. The longer is the segment of rational investment, the faster is the process of returning the funds invested in the development. At the same time, $\mathrm{I}_{2}$ and $\mathrm{I}_{4}$ in Fig. 1 correspond to critical production volumes. If investment in the development of an enterprise is less than $\mathrm{I}_{1}$ and more than $\mathrm{I}_{4}$, it is most likely not to be returned.

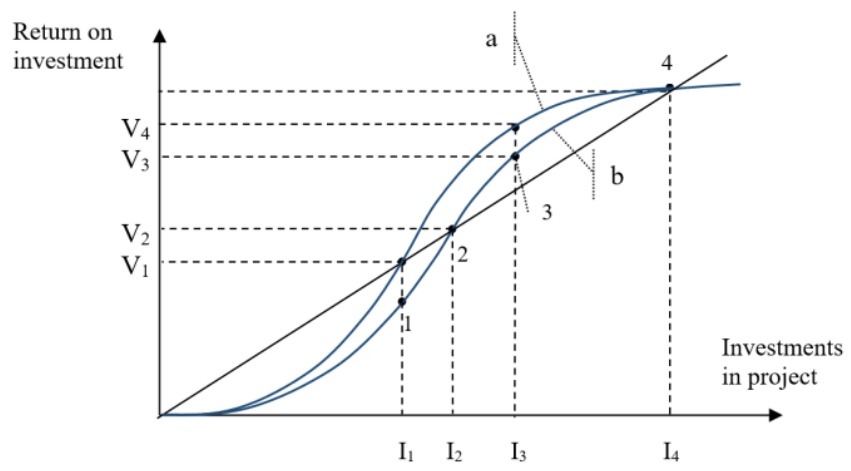

Fig. 1. The dependence of the position of the S-curve in a given field of coordinates from the labor quality

Logically, we assume that advanced personnel with a higher level of quality implements a development project more effectively, i.e. with the same amount of investment, it shows better results than a less developed team., This position is graphically represented by a new $\mathrm{S}$-curve, located above the respective curve of a less developed team (curve "a" in Fig. 1). The figure shows that with the same level of investment in an organizational development project, for example, $\mathrm{I}_{3}$, the return of a highly developed team will be $\mathrm{V}_{4}$, while a less developed team will provide return on investment only at the level $\mathrm{V}_{3}$. At the same time, there is an expansion of the rational investment interval to $\mathrm{I}_{1}-\mathrm{I}_{4}$, while investment in a critical volume decreases, $I_{1} \pi I_{2}$. Thus, with an increase in the labor quality of the organization, its $S$-curve moves up and to the left in a given field of coordinates.

While exploring the possibility of modeling the economic processes in the organization, we faced the problem of quantifying the S-curve displacement in the specified coordinate field. This problem, in our opinion, can be solved if another management tool, namely, an experience curve is used.

The experience curve was first plotted in the late 1960s by the Boston Consulting Group (BCG) during a survey of the manufacture of aircraft fuselages at Boeing factories $[9, \mathrm{p} .171]$. Its meaning comes down to the fact that when practical experience is gained, unit production costs can be reduced. A quantitative characteristic of this effect was obtained: every time the production volume is doubled, the unit costs fall by about 15-30\%, depending on the characteristics of the production process (Fig. 2). The dependence of the shape of the experience curve on the level of personnel development is also recorded. A developed team reduces production costs more intensively in the process of performing repetitive manufacturing operations in comparison with a less developed team. Its experience curve (curve 2 in Fig. 2) is steeper with respect to the similar curve of a less developed team (curve 1 in Fig. 2).

Thus, in accordance with the experience curve, when we improve the labor quality, there is a reduction in unit costs, mainly due to a decrease level of rejects in production, a better use of technology and capabilities of the machine system, adjustment of processing modes and a reduction in material and other resources used in production process, productivity growth and a relative fall in the labor costs... The list of factors affecting the reduction of unit production costs can be extended. In fact, these are the same factors that are involved when plotting the corresponding S-curve, which reflects the development of the organization. Thus, it is necessary to recognize the fact that the basis for determining the essential content of both tools turns out to be the same.

Analyzing the correspondence of the experience curves of labor teams with different development levels (Fig. 2) shows that when both teams have the same initial experience in a given job, the developed team (with a higher labor quality) at the beginning of the production process quickly increases the rate of its mastering. Then, with an increase in production volumes, the rates are reduced and in case of very large volumes, most likely, all other things being equal, the unit costs of both teams will be about the same.

The abovementioned information is visually represented in Fig. 2, showing that with an increase in production, there is a decrease in unit costs, first at a relatively high rate, and then this rate is decreasing.

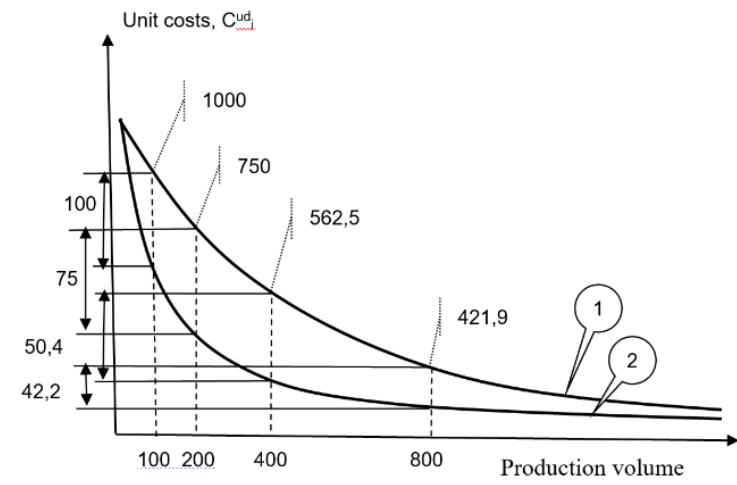

Fig. 2. Experience curves 
So, if we assume that the volume of production $N_{1}=100 p c s$, and the unit costs at that volume $C_{1.1}^{u d}=1000 \mathrm{rub} / \mathrm{pce}$, then with a doubling of the volume of production, i.e. its growth to the value $N_{2}=200 p c s$, the unit costs will fall by $15-30 \%$, they will be equal $C_{1.2}^{u d} \cong 850 \div 700 \mathrm{rub} /$ pce (see Figure 2 ). Costs decrease in absolute terms by 150-300 rubles per unit. With the next doubling of production, this reduction will be only 128-210 rub/pce, etc. As we already mentioned, the highly developed team reduces unit production costs faster than the underdeveloped team. When working with a fixed production volume, the more developed team (curve 2 in Fig. 2) will result in lower unit costs than a relatively poor team (curve 1 in Fig. 2), i.e. $C_{2}^{u d} \pi C_{1}^{u d}$. The resulting difference in costs $\Delta C^{u d}=C_{1}^{u d}-C_{2}^{u d}$ can be explained only by a higher quality of work, which is demonstrated by the second team, who managed to accumulate production experience faster than the competitor, improve product design and production technology faster, organize the entire production process, supply processes and product sales at a higher level, etc.

If we rely on the data presented by T. Schultz, then we can estimate the decrease in unit costs due to a higher labor quality. To demonstrate this approach, let us take the value of unit cost reduction equal to $10 \%$ (potential experience according to T. Schultz). Then curve 2 in Fig. 2, corresponding to the team with higher qualifications, general educational level, wider outlook, greater motivation, etc., can be constructed. Let us call it the predictive experience curve (curve 2 in Fig. 2). In this case, it becomes possible to determine another important information effect. If at a fixed production volume of $\mathrm{N}$, the unit costs decrease by about $10 \%$, i.e. $C_{2}^{u d}=0.9 \cdot C_{1}^{u d}$, the savings on 1 piece of the product (single job) will be $\Delta C^{u d}=C_{1}^{u d}-C_{2}^{u d} \cong 0.1 \cdot C_{1}^{u d}$. If the saved funds are returned to production, then the highly developed team creates additional internal investment (see Figure 2), which can be calculated using formula (2)

$$
\Delta^{i n}=\Delta C^{u d} \cdot N=\left(C_{1}^{u d}-C_{2}^{u d}\right) \cdot N=0.1 \cdot C_{1}^{u d} \cdot N
$$

To determine the calculations, the choice of the experience curve shape should be justified. This can be done based on the empirical data on the production costs of the enterprise contained in the reporting documentation, as well as on the basis of the recommendations presented in $[9$, p.171-174], [11, p.58-60].

The above can be demonstrated by a simulated example. We assume that the shape of the experience curve under the example conditions corresponds to a decrease in the unit costs for each doubling of production volumes by about $25 \%$, i.e. there is a $75 \%$ experience curve. In this case, in the initial state with $\mathrm{N} 1=100$ pcs. unit costs will be $C_{1}^{u d}=1000$ rub/ pce (see Table. 1).

According to the data contained in columns 1 and 2 of the Table 1, the curve of accumulated experience can be plotted (curve 1 in Fig. 2).

The next stage of the research involves the justification of the rate of return on the basis of potential experience. According to Schultz, for the United States this rate is $8-10 \%$ (for Russia, these figures are lower and should be defined on the basis of the organization's practical activities) [1], [8]. In the example, this parameter is assumed to be $10 \%$. Now we can calculate the reduction of unit costs due to the involvement of better labor resources in the production process. The results are as follows:

$$
\begin{gathered}
\Delta C_{1}^{u d}=C_{1}^{u d}-C_{2}^{u d} \cong 0.1 \cdot C_{1}^{u d}=0.1 \cdot 1000=100 \mathrm{rub} / \mathrm{pce} \\
\Delta C_{2}^{u d} \cong 0.1 \cdot C_{2}^{u d}=0.1 \cdot 750=75 \mathrm{rub} / \mathrm{pce} . \\
\Delta C_{3}^{u d} \cong 0.1 \cdot C_{3}^{u d}=0.1 \cdot 562.5=50.4 \mathrm{rub} / \mathrm{pce} \\
\Delta C_{4}^{u d} \cong 0.1 \cdot C_{3}^{u d}=0.1 \cdot 421.9=42.2 \mathrm{rub} / \mathrm{pce}
\end{gathered}
$$

The obtained calculated values are summarized in column 3 of the Table 1.

The value of additional internal investment, formed by a more developed team, can be calculated by formula (2), i.e.:

$$
\begin{aligned}
& \Delta_{1}^{\text {in }}=\Delta C_{1}^{u d} \cdot N_{1}=0.1 \cdot C_{1}^{u d} \cdot N_{1}=0.1 \cdot 1000 \cdot 100=10000 \mathrm{rub} . \\
& \Delta_{2}^{\text {in }}=\Delta C_{2}^{u d} \cdot N_{2}=0.1 \cdot C_{2}^{u d} \cdot N_{2}=0.1 \cdot 750 \cdot 200=15000 \mathrm{rub} . \\
& \Delta_{3}^{\text {in }}=\Delta C_{3}^{u d} \cdot N_{3}=0.1 \cdot C_{3}^{u d} \cdot N_{3}=0.1 \cdot 562.5 \cdot 400=22500 \mathrm{rub} . \\
& \Delta_{4}^{\text {in }}=\Delta C_{4}^{u d} \cdot N_{4}=0.1 \cdot C_{4}^{u d} \cdot N_{4}=0.1 \cdot 421.9 \cdot 800=33752 \mathrm{rub} .
\end{aligned}
$$

These calculation results are shown in column 4 of Table 1 .

Investments in the development of the enterprise (in the extended sense) can be calculated as a product

$$
\begin{aligned}
I_{i}=N_{i} \cdot C_{i}^{u d}, \text { i.e. } \\
I_{1}=100 \cdot 1000=100000 r u b . \\
I_{2}=200 \cdot 750=150000 r u b . \\
I_{3}=400 \cdot 562.5=225000 r u b . \\
I_{4}=800 \cdot 421.9=337520 r u b .
\end{aligned}
$$

The calculation results are listed in column 5 of Table 1 . 
TABLE I. INITIAL AND DESIGN PARAMETERS OF THE ENTERPRISE

\begin{tabular}{|c|c|c|c|c|c|}
\hline $\begin{array}{l}\text { Producto } \\
\text { n volube } \\
\mathrm{N}_{\mathrm{i}}, \text { pcs. }\end{array}$ & $\begin{array}{c}\text { Unit } \\
\text { costs, } \\
\text { rub/pce }\end{array}$ & $\begin{array}{l}\Delta C_{i}^{u d} \\
\text { rub/pce }\end{array}$ & $\begin{array}{c}\Delta_{i}^{i n} \\
\text { ths.ru } \\
\quad \text { b }\end{array}$ & $\begin{array}{l}\text { Investment } \\
\qquad \mathrm{s} \text { in } \\
\text { developme } \\
\text { nt project, } \\
\mathrm{I}_{\mathrm{i}} \text { ths.rub. }\end{array}$ & $\begin{array}{l}\text { Return on } \\
\text { investment } \\
\mathrm{V}_{\mathrm{i}} \text {, ths.rub. }\end{array}$ \\
\hline 1 & 2 & 3 & 4 & 5 & 6 \\
\hline $\mathrm{N}_{1}=100$ & $\begin{array}{l}\mathrm{C}^{\mathrm{ud}}=100 \\
0\end{array}$ & 100 & 10 & $\mathrm{I} 1=100,000$ & $\mathrm{~V} 1=50,000$ \\
\hline $\mathrm{N}_{2}=200$ & $\mathrm{C}^{\mathrm{ud}}{ }_{2}=750$ & 75 & 15 & $\mathrm{I} 2=150,000$ & $\begin{array}{c}\mathrm{V} 2=150,00 \\
0\end{array}$ \\
\hline $\mathrm{N}_{3}=400$ & $\begin{array}{l}\mathrm{C}_{3}{ }_{3}^{\mathrm{ud}}=562 . \\
5\end{array}$ & 56.25 & 22.5 & $\mathrm{I} 3=225,000$ & $\mathrm{~V} 3=292.5$ \\
\hline $\mathrm{N}_{4}=800$ & $\begin{array}{l}\mathrm{C}_{4}^{\mathrm{ud}}=421 . \\
9\end{array}$ & 42.2 & 33.8 & $\mathrm{I} 4=337,520$ & $V 4=371.5$ \\
\hline
\end{tabular}

Column 6 of Table 1 contains data (simulated in this case) obtained empirically as a result of the enterprise development project.

Using the information contained in columns 5 and 6 of Table 1, an empirical S-curve can be constructed. First, points are marked on the indicated coordinates, then we unite this points with a line which will give us an empirical S-curve. The construction is shown in Fig.3.

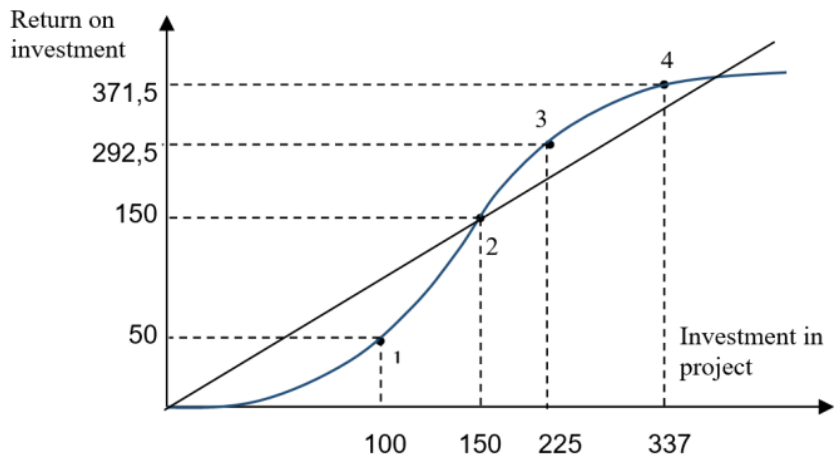

Fig. 3. Construction of empirical S-model

Based on the empirical data, the S-curve allows us to make a theoretical S-model by selecting the coefficients in the updated Verhulst model proposed by us (1). The construction procedure is given in [11].

Based on the information obtained, it seems possible to estimate the displacement of the S-curve, which can be obtained using the following approach.

The theoretical S-model makes it possible to construct a predictive S-curve (curve 2 in Fig. 1) by calculating a certain number of points using the above formula (2). The meaning of these calculations is defined by the fact that, because additional internal investment is formed, its return will be higher than that of the less developed team. So when investment in the development of the company is equal to $\mathrm{I}_{1}$, the well-developed team forms additional internal investment in the amount of $\Delta_{1}^{i n}$ (see Fig.4). As a result, the return on investment in the production process will increase to a volume of $\mathrm{I} 2=\mathrm{I} 1+\Delta_{1}^{i n}$. This amount of investment forms the return at the level of V2. Thus, the investment I1 will correspond to the return V2. Point "a" with coordinates (I1; V2) is marked (see Fig.4). Similarly, points "b", "c", ... "k" can be built for any amount of funds invested in the organizational development project (I3, I4, .. Ik).

Return on investment

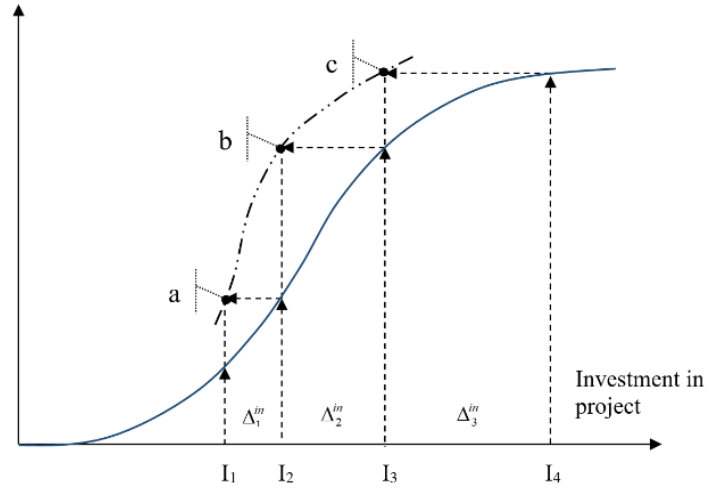

Fig. 4. Construction of predictive S-curve

Based on the marked points in the given coordinate field, a line is constructed, which is the predictive S-curve that determines the process of return on investment by the production team with a higher quality of labor resource. This predictive S-curve will allow us to evaluate the impact of the quality of labor resources involved in the production process on the important economic indicators of the enterprise, namely:

- to evaluate a new, extended range of rational investments in the development of the enterprise;

- to define the sub-optimal amount of investment, and therefore the most effective activity range of the enterprise;

- to estimate the effectiveness of investments in the development of the labor resources of the enterprise. Such estimation, in our opinion, should be carried out by controlling the ratio of the value of the formed additional internal investment to the labor team and the volume of investment made in the development of the labor team. This ratio should be non-negative, i.e. $E=\Delta^{\text {in }}-I \geq 0$.

In the study dedicated to assessing how the quality of labor resources affects the efficiency of production activity, we relied on the data obtained by two Nobel prize winners for the analysis of the statistics relevant for the USA which says that, on average, every dollar invested in education, experience gained by the personnel, etc. brings a certain benefit to an enterprise. With limited investment resources the technique we suggest makes it possible to know how to be effective in their rational distribution between labor and capital. Quantitative evaluation of the impact the level of labor quality has on return on investment is an interesting and promising direction for our further research.

Thus, the methodology for assessing the impact of the quality of labor resources on the results of the enterprise's activities has the following phases:

1. The necessary data are collected using the reporting information on the economic activities of the enterprise.

2. The S-curve of the correspondence of the returns on investments in the development project to their volume is built on the basis of the retrospective data on the economic activity of the enterprise. 
3. The S-curve that was constructed on empirical data serves as a basis to make a logistic dynamics model ( $\mathrm{S}$-model), which should be built on the basis of the updated Verhulst model (1) by choosing coefficients $A, a$ and $b$. The method of such a selection is presented in [4, p. 195-211].

4. The experience curve is constructed, being the characteristic for this particular organization in a certain area of its economic activity. This takes into account all the unique characteristics of the company.

5. A justification is carried out for the growth of the potential experience rate of return (according to Schultz) while this experience is accumulated during the production process.

6. Based on the accepted rate of return of potential experience, a predictive experience curve is constructed.

7. Using the experience curves built in phases 4 and 6 , the amount of possible internal additional investment (formed due to an increase in the labor quality of the organization) in the production process $\Delta^{i n}{ }_{i} \mathrm{~s}$ is calculated.

8. The "movement" of the S-curve is calculated when using internal additional investments $\Delta^{i n}{ }_{i}$ and the predictive $S$ curve is constructed taking into account the corresponding increase in the labor quality of the organization.

9. A theoretical S-curve is constructed according to the updated Verhulst model (1) by adjusting the coefficients in accordance with its offset enabled by the growth of the quality of labor resources, formed due to additional internal investment $\Delta^{i n}{ }_{i}$

10. Using the obtained model, a rational investment interval is calculated for the enterprise development project; the suboptimal volume of investment for the enterprise development project is calculated; the effectiveness of the investment made in the organizational development project.

11. The profitability of investment in the growth of the labor quality and other economic indicators of the enterprise are determined.

\section{CONCLUSIONS}

1. The integrated use of such management tools as experience curves and logistic dynamics models ( $\mathrm{S}$-models) provides a significant amount of information about the production system, which increases certainty in the process of making management decisions about the development of a company. 2. The information basis for constructing experience curves and S-models has a generalized, complex nature, which ensures their essential identity.

3. The updated Verhulst model turns out to be more acceptable for describing the economic processes occurring at the enterprise.

4. Modeling based on the proposed management tools allows us to optimize the use of limited investment opportunities of the enterprise, contributes to a growth in the effectiveness of investment;

5. The development of labor resources of the enterprise is a key direction that ensures that its competitive positions are strengthened in the long run;
6. The practice of applying the experience curves and Smodels requires further research, as well as theoretical substantiation of some poorly elaborated methodology elements, and comprehensive testing of the proposed guidelines in practice.

Further research, in our opinion, should include:

- Searching for an acceptable solution to the system of equations that determine the rational interval for investment in organizational development projects, primarily industrial enterprises.

- Improving the methodology for determining the optimal amount of investment in development projects with the involvement of theoretical models of logistic dynamics.

- Checking the scalability of the organization's S-models when implementing various investment projects.

- Developing a methodology for constructing an empirical model of mastering in practice (experience curve);

- Conducting research to determine the rate of return of "potential" experience for every specific labor team, production process, and type of activity.

- Quantitative evaluation of the level of the labor force quality of the enterprise

\section{REFERENCES}

[1] https://www.researchgate.net/publication/316854614_LAUREAT_N OBELEVSKOJ_PREMII_PO_EKONOMIKE_TEODOR_SULC_O_ ROLI_CELOVECESKOGO_KAPITALA_V_PREODOLENII_PRO BLEM_BEDNOSTI].

[2] Becker G.S. Human Capital: A Theoretical and Empirical Analysis. N.Y.:Columbia University Press for NBER, 1964

[3] Becker G. Do not spare money for people // «Business week»: 1996. No 6.

[4] Leslie L., Brinkman P. The Economic Value of Higher Education. N.Y.: Macmillan Publishing Company, 1988.

[5] Dyatlov S.A., Davydova O.A. Examples of calculating the economic efficiency of investment in the education of the individual. $\mathrm{SPb}$.: SPbSUE: 2000. - P.15.

[6] Ivanyushchenkova M., Fukolova Y. Borrowed mind // Kommersant Money. 1998. No 1 (155), 21 january.

[7] Genkin B.M. Economics and sociology of labour: textbook / B.M. Genkin. - 8th ed. - Moscow: Norma, 2012. - 464pp.

[8] Vlasov M.P., Shimko P.D. Modeling of economic processes: textbook. ENGECON, 2006. - 388 p.

[9] Arthur Thompson, John Formby. Economics of the firm / Trans. from English - Moscow: Publishing House BINOM, 1998. - 544 pp.

[10] Kruglov M. I. Strategic management of the company: Textbook for universities. Moscow: Russian Business Literature, 1998.

[11] Malyuk V.I., Radaev A.E., Silkina G.Yu. Substantiation methods of the characteristics of the process of industrial enterprises development using the tools of optimization modeling // Scientific and technical journal of SPbGPU. Economics sciences. 2018. Vol. 11, No. 6. P. 195211. DOI: $10.18721 /$ JE.11617

[12] Malyuk V.I. Strategic management. Organization of strategic development: a textbook and a manual for bachelors and masters / V.I. Malyuk. - Moscow: Yurait Publishing House, 2016. - 361 p. - Series: Bachelor and Master. Module.

[13] Practicum on logistics: Textbook/ Ed. Prof. BA Anikin. Moscow: INFRA-M, 2000.

[14] Trenyov N.N. Enterprise and its structure: Diagnostics. Control. Rehabilitation. Textbook for universities. Moscow: Publishing house PRIOR, 2000.

[15] V. Malyuk and A.Danilov, Modeling of the investment project of construction the cottage settlement, MATEC Web of Conferences, Vol. 170, 01090 (2018) 
[16] Verhulst, P. F., Recherches Mathématiques sur La Loi D'Accroissement de la Population, Nouveaux Mémoires de l'Académie Royale des Sciences et Belles-Lettres de Bruxelles, 18, Art. 1, 1-45, 1845.

[17] MICHAEL J. PANIK, GROWTH CURVE MODELING. Theory and Applications. Department of Economics, University of Hartford, West Hartford, Connecticut Copyright $@ 2014$ by John Wiley \& Sons, Inc. All rights reserved. Published by John Wiley \& Sons, Inc., Hoboken, New Jersey. Published simultaneously in Canada. 